\title{
Nonlinear Power Inductors for Large Current Crest Factors
}

\author{
Alexander Stadler, Tobias Stolzke, and Christof Gulden \\ STS Spezial-Transformatoren-Stockach GmbH \& Co. KG, Am Krottenbühl 1, 78333 Stockach, Germany \\ Correspondence should be addressed to Alexander Stadler; stadler@sts-trafo.de
}

Received 11 December 2012; Accepted 13 March 2013

Academic Editor: Jiun-Wei Horng

Copyright (C) 2013 Alexander Stadler et al. This is an open access article distributed under the Creative Commons Attribution License, which permits unrestricted use, distribution, and reproduction in any medium, provided the original work is properly cited.

A practical method is presented: how to adjust the inductance curve of a nonlinear (saturable) inductor with respect to a desired shape. For this purpose, a nonlinear model was developed based on finite element method (FEM). It is shown how a highly efficient construction with low stray fields and maximum package density can be achieved. Different prototype inductors were realized to illustrate the practical capability of photovoltaic (PV) inverters as well as active power factor correction (PFC) applications. All simulations are verified by means of experimental data drawn from electrical measurements.

\section{Introduction}

A nonlinear shape of inductance is generally preferred if the peak inductor current is much higher than its effective current (high crest factor). This is typical for active power factor correction (PFC) systems [1]. Higher inductance leads to lower ripple currents and thus to reduced losses. Nevertheless, a certain drop of the inductance can be accepted at full power due to the fact that full power only occurs for short times in praxis. For example, in photovoltaic (PV) inverter applications, a volume- and cost reduction of 10 up to 20 percent can be achieved using a nonlinear inductor instead of a linear one [2]. The paper describes an optimized construction based on low permeable Sendust (CoolM $\mu$ ) material (Figures 1 and 2). Due to magnetostriction close to zero (low noise) and moderate core losses at higher frequencies, the chokes are applicable for PV inverters as well as active PFC. Using the design methodology described later, a desired shape of the $L(I)$ curve can be obtained with low stray fields, minimum losses, and a maximum level of package density.

\section{Inductance Simulation}

2.1. Material Curves. To describe the saturation behavior of the material, the (static) $\mathrm{BH}$-curves and differential permeabilities have to be measured considering different temperatures. For this purpose, ring core specimens were grinded out carefully from the available core material. To assure a perfectly closed magnetic circuit, particularly in deep saturation, these toroids have to be equipped with equally distributed single-layer windings.

The material curves were finally extracted from measurements according to the standards [3]. Figure 3 shows the equivalent circuit diagram of the test set-up.

To describe the magnetization curve and to inter- and extrapolate measured data, the rational expression

$$
B=\mu_{0}(H+M)=\mu_{0}\left(H+\frac{a_{1} H+a_{2} H^{2}}{1+b_{1} H+b_{2} H^{2}}\right)
$$

is applied [4]. $B, H$, and $M$ in (1) denote the magnetic flux density, the magnetic field strength, and the magnetization. The parameters $a_{1}, a_{2}, b_{1}$, and $b_{2}$, are used to adapt to measured data. The measurement results are depicted by Figures 4 and 5.

2.2. FEM Model and Verification. To be able to predict the inductance curve $L(I)$ of arbitrary core- and winding configurations [5-7], the static material curves shown in Figures 4 and 5 were implemented into a numerical field solver based on finite element method (FEM). It could be shown that the influence of the frequency can be neglected in practical applications using conventional ferrites and Sendust metal powder [8] as well. Thereby it became possible to 


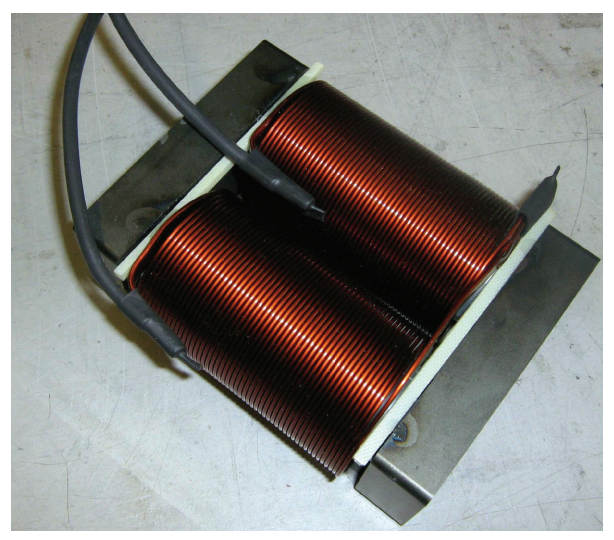

FIgURE 1: Power inductor with helical flat wire windings.

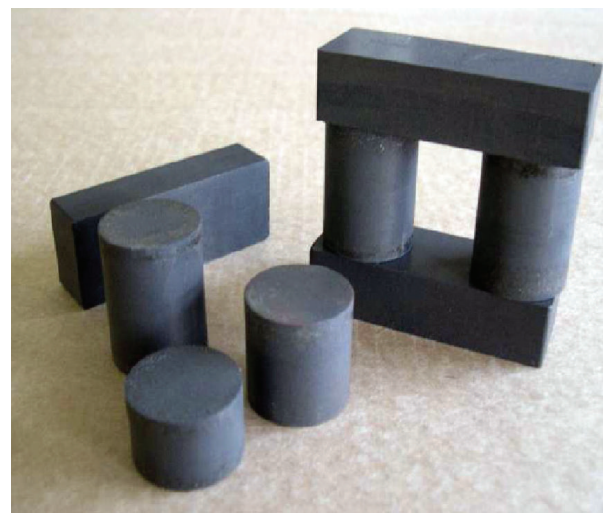

FIGURE 2: Low permeable block and cylindrical Sendust $(\operatorname{CoolM} \mu)$ metal powder cores.

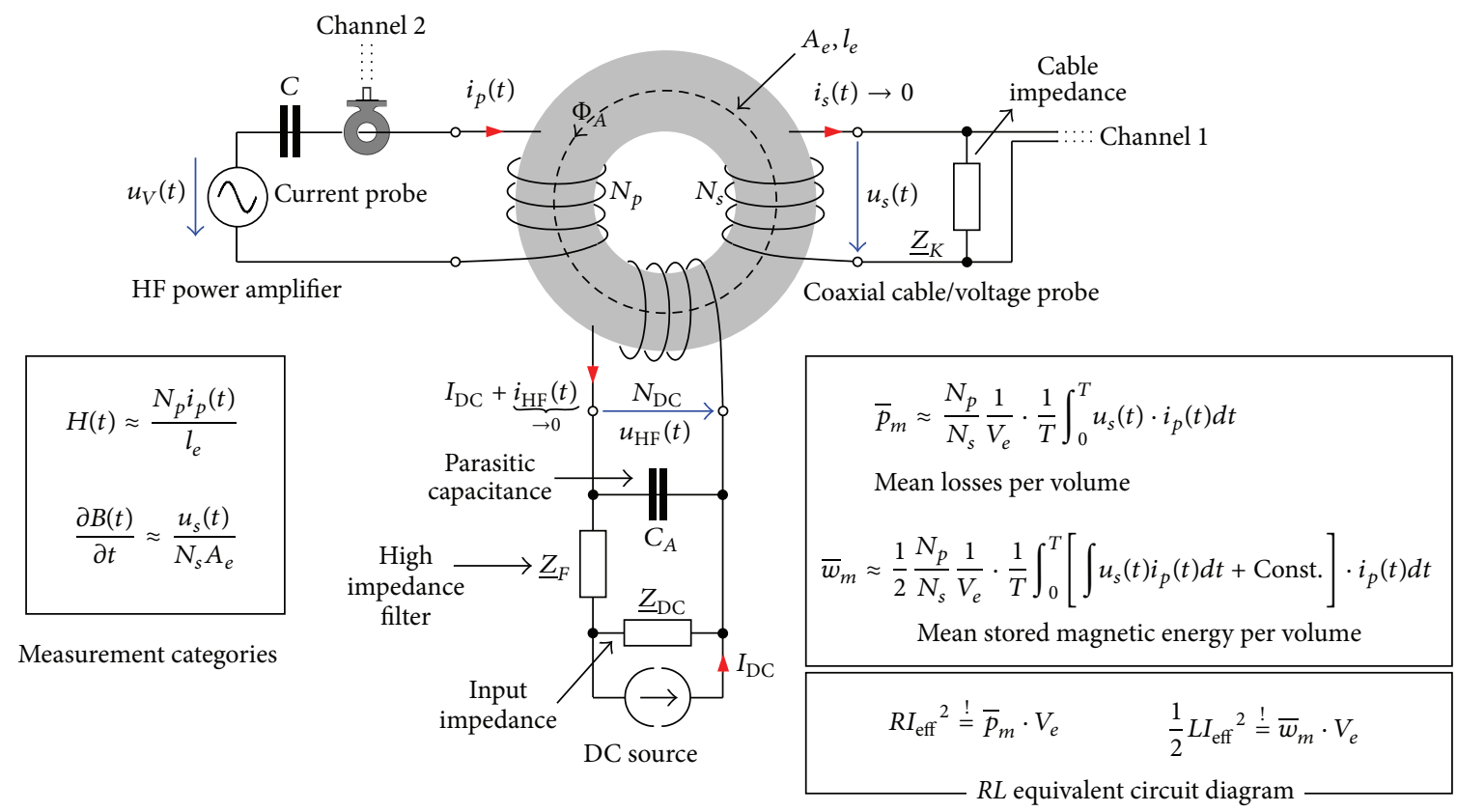

FIGURE 3: Equivalent test set-up to determine the material parameters according to the standards [3]. 


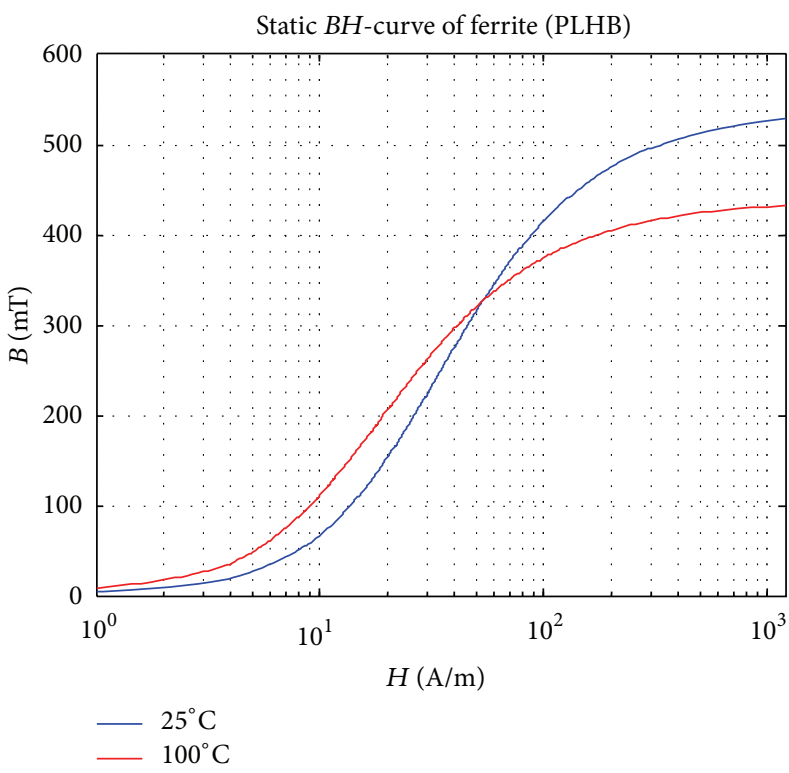

(a)

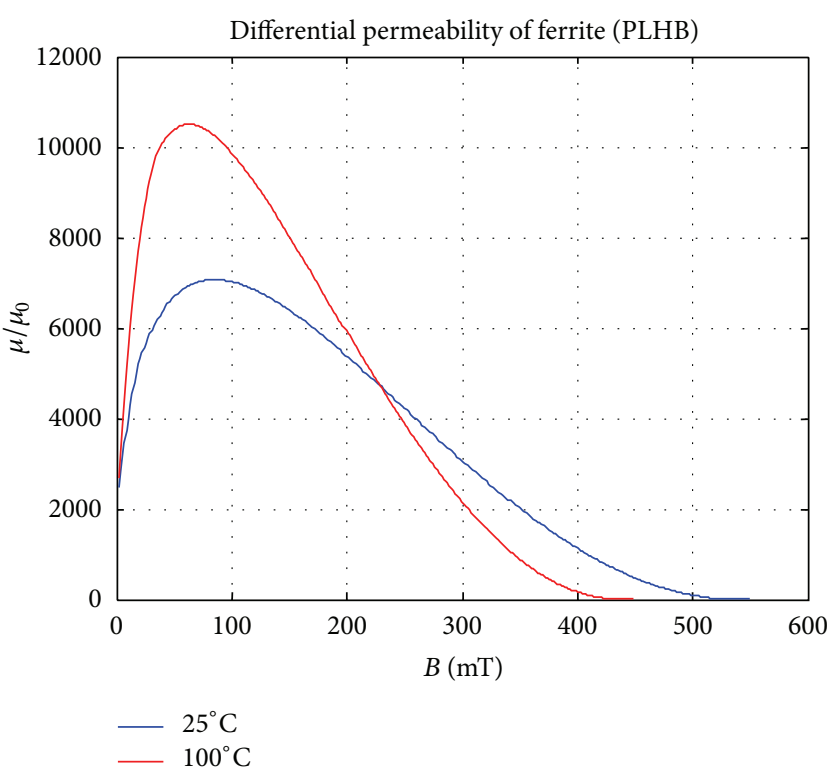

(b)

Figure 4: Measured static $\mathrm{BH}$-curves (a) and differential permeabilities (b) of Samwha (PLHB) ferrite at $25^{\circ} \mathrm{C}$ and $100^{\circ} \mathrm{C}$.

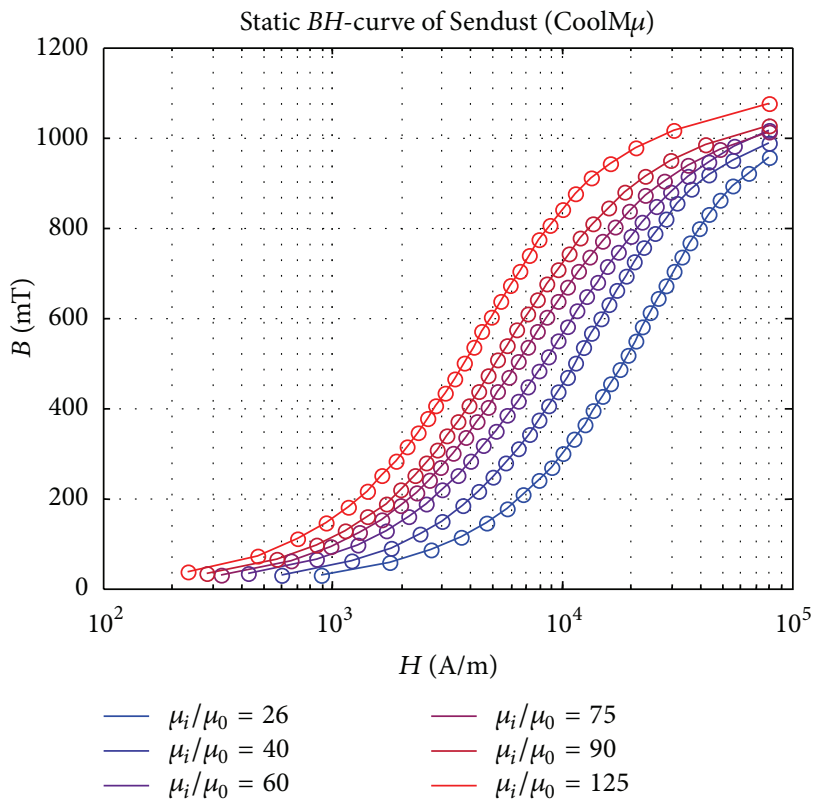

(a)

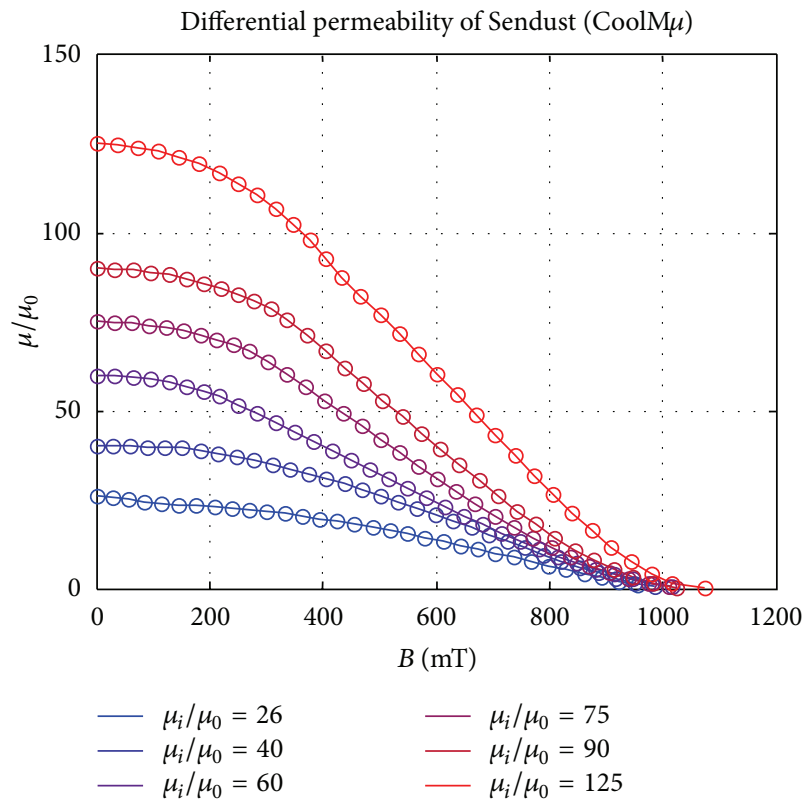

(b)

Figure 5: Measured static $B H$-curves (a) and differential permeabilities (b) of Sendust (CoolM $\mu$ ) metal powder with different permeability grades.

reduce the nonlinear simulation to a static approach with the advantage of considerably lower simulation time (110 minutes) and better convergence behavior of the solver. Figure 6(a) depicts the field pattern (reduced to one-fourth by symmetries) of a saturated URR 30 core (legs built up from ferrite disks with $30 \mathrm{~mm}$ diameter and circular cross-section, block yokes) after convergence.
To demonstrate the practical capability of the algorithm, a central $20 \mathrm{~mm}$ hole was grinded out of the central ferrite disks. Hence, a stepped shape of the inductance curve $L(I)$ is expected. Figure 6(b) shows a comparison of the simulated and measured results. A commercial Wayne-Kerr bridge with an adjustable DC bias unit of $0 . .125 \mathrm{~A}$ and $1 \mathrm{~V}$ constant AC voltage was used for testing. To demonstrate that the effect 


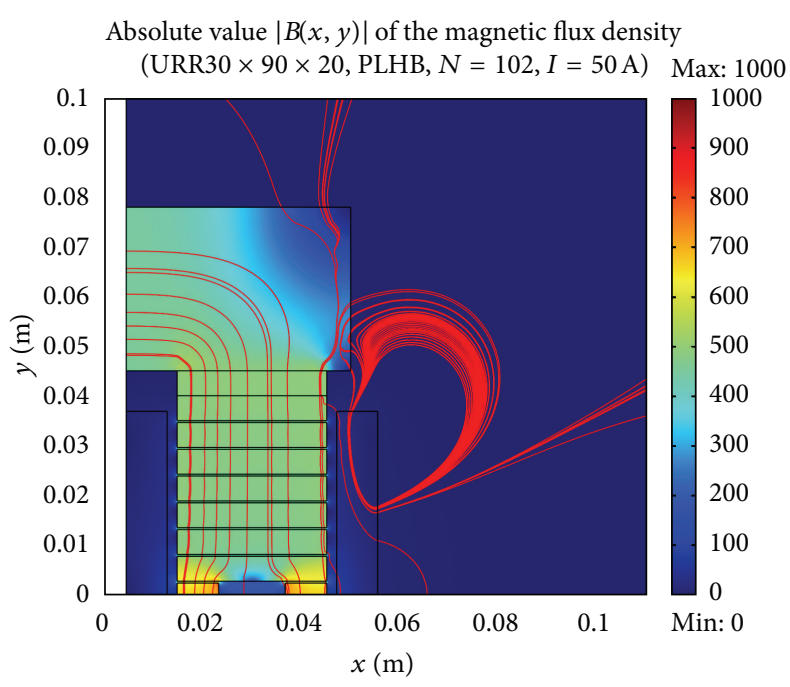

(a)

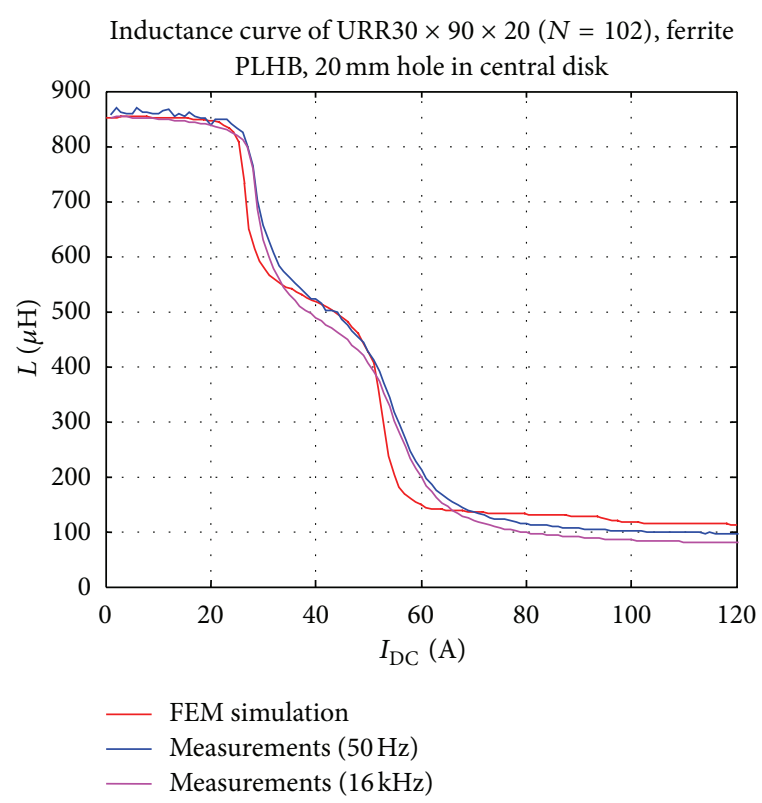

(b)

FIgure 6: Distribution of the magnetic flux density $|B(x, y)|[\mathrm{mT}]$ inside the URR $30 \times 90 \times 20$ core (legs built up from ferrite disks with $30 \mathrm{~mm}$ diameter and circular cross-section, block yokes): (a) simulated and measured inductance curves, $(\mathrm{b})\left(\mathrm{PLHB}, N=102, I_{\mathrm{DC}}=50 \mathrm{~A}\right.$, $20 \mathrm{~mm}$ hole in central disk).

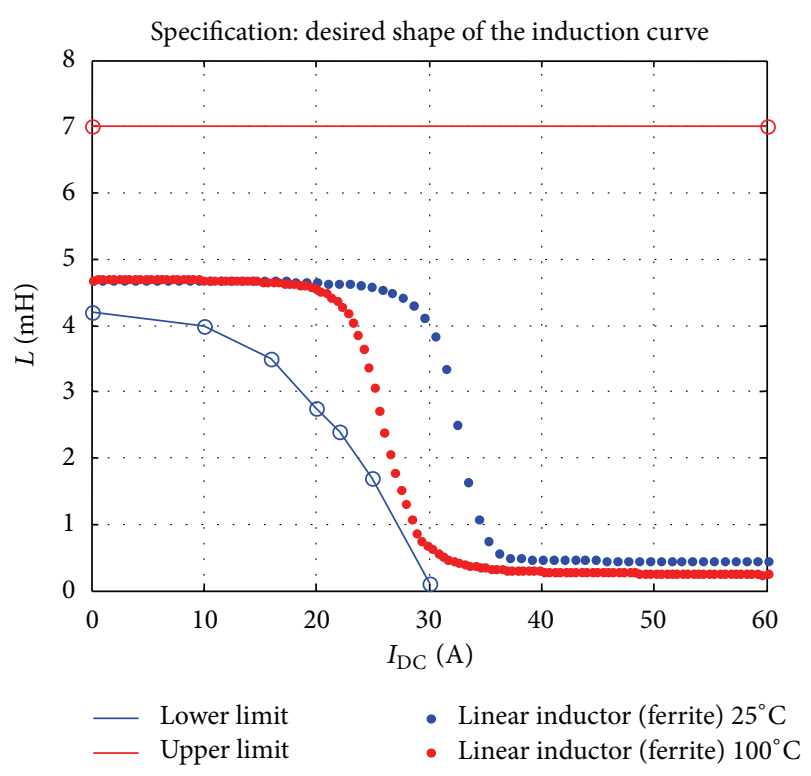

FIGURE 7: Example specification: Given lower and upper inductance limits with typical inductance curves of a (conventional) linear ferrite inductor at $25^{\circ} \mathrm{C}$ and $100^{\circ} \mathrm{C}$.

of frequency can be neglected, the curves were measured at $50 \mathrm{~Hz}$ as well as at $16 \mathrm{kHz}$ (the switching frequency in the application). Considering a multitude of measurement errors during material data extraction, the divergence between simulated and measured results is adequate in praxis-even if the complex geometry is restricted to $2 \mathrm{D}$.

\section{Parameter Study}

Figure 7 shows an example specification of a $15 \mathrm{~kW}$ PV input inductor (boost converter). The inductance curve of the practical component has to stay within the given limits. To keep the specified lower limit at $25 \mathrm{~A}$, a (conventional) linear ferrite inductor far exceeds the cost-optimum lower inductance limits at lower currents. Due to the distinct saturation behavior of the ferrite material, no further adaptation and thus size/cost reduction are possible. Of course, shape giving grinding of the ferrite could help here, but with the disadvantage of (a) concentrated air gap(s). This would lead to considerably increasing copper losses and/or higher radiated emission of the component. As a conclusion, a mix of high and low permeable material offers the best opportunity to adjust the inductance curve to the desired shape. A design procedure is found as follows.

Due to the fast calculation time, the developed model can be used for various parameter studies. Thus, variants based on different combinations of available materials and parts can be considered for simulation and finally selected with the best-fit inductance curve $L(I)$ as a criterion.

In Figure 8(a) the influence of the yoke's permeability at $25^{\circ} \mathrm{C}$ is depicted (legs built up from ferrite disks with $50 \mathrm{~mm}$ diameter and circular cross-section, distributed air gap). In each case, the necessary number of turns is adapted to equal small signal inductance $L(I \rightarrow 0)$. Figure $8(\mathrm{~b})$ shows comparable results at $100^{\circ} \mathrm{C}$. Temperature effects can be referred to as the ferrite material only because the material parameters of Sendust metal powder are hardly affected by the temperature. 


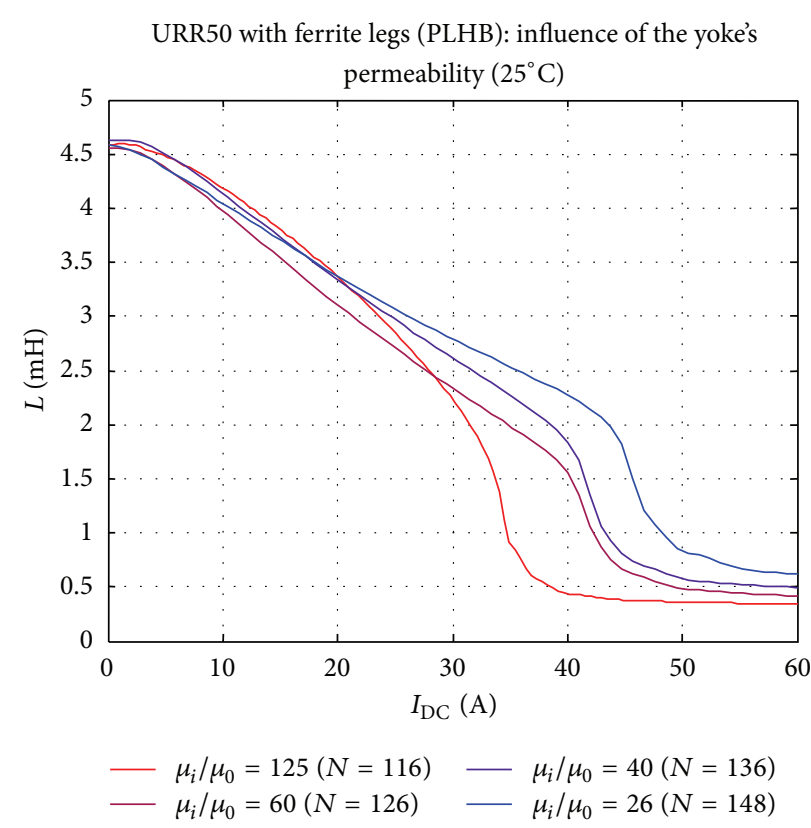

(a)

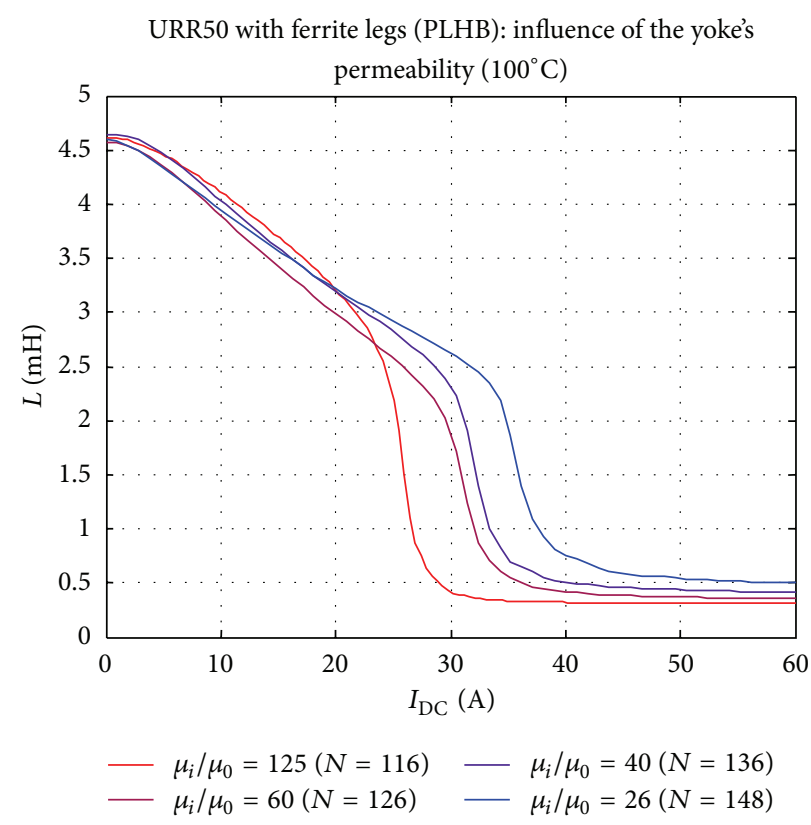

(b)

Figure 8: Parameter study: inductance curves at $25^{\circ} \mathrm{C}$ (a) and $100^{\circ} \mathrm{C}(\mathrm{b})$ using Sendust (CoolM $\mu$ ) yokes of different permeability grades.

URR50 with ferrite legs (PLHB) and Sendust $\mu_{i} / \mu_{0}=125$

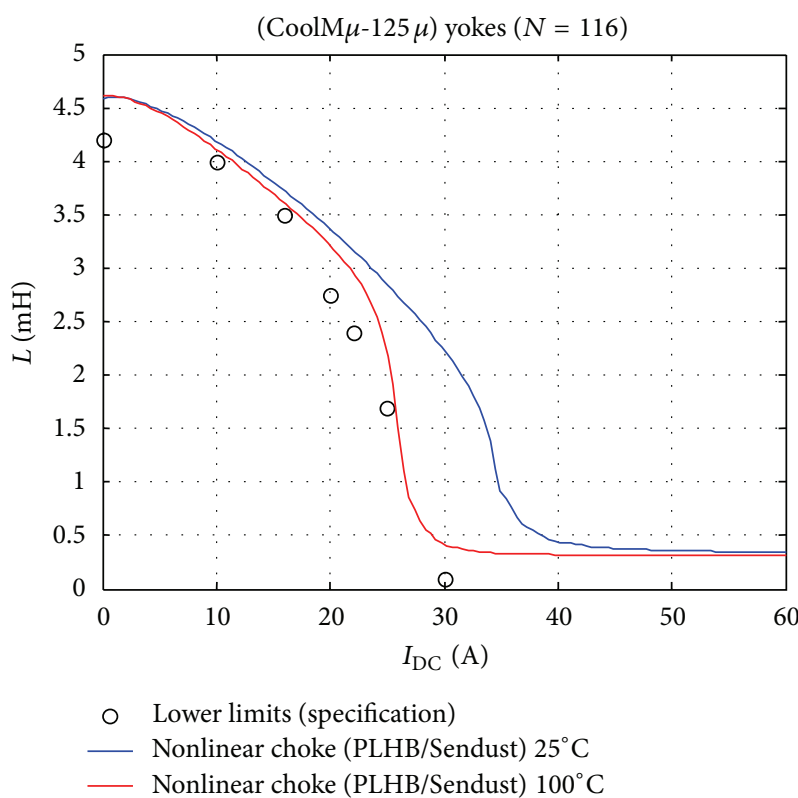

FIGURE 9: Inductance curves of the optimized nonlinear (saturable) inductor meet specification at $25^{\circ} \mathrm{C}$ as well as $100^{\circ} \mathrm{C}$.

\section{Results}

Now the best-fit configuration can be selected from the parameter studies described previously. It is found that block yokes of Sendust $(\operatorname{CoolM} \mu)$ metal powder with a relative (small signal) permeability $\mu_{i} / \mu_{0}=125$ are optimum.
TABLE 1: Comparison between conventional and nonlinear (saturable) inductor.

\begin{tabular}{lccc}
\hline & $\begin{array}{c}\text { Conventional } \\
\text { inductor }\end{array}$ & $\begin{array}{c}\text { Nonlinear } \\
\text { (saturable) inductor }\end{array}$ & Trend \\
\hline Size & $166 \times 140 \times 85 \mathrm{~mm}$ & $113 \times 140 \times 85 \mathrm{~mm}$ & - \\
Volume & $1975 \mathrm{~cm}^{3}$ & $1344 \mathrm{~cm}^{3}$ & $-32 \%$ \\
Weight (core) & $5.44 \mathrm{~kg}$ & $5.17 \mathrm{~kg}$ & $-5 \%$ \\
Weight (copper) & $1.98 \mathrm{~kg}$ & $1.60 \mathrm{~kg}$ & $-19 \%$ \\
Number of turns & 144 & 116 & $-19 \%$ \\
Losses (copper) & $24 \mathrm{~W}$ & $19.44 \mathrm{~W}$ & $-19 \%$ \\
Losses (core) & $8 \mathrm{~W}$ & $9.36 \mathrm{~W}$ & $+17 \%$ \\
Losses (total) & $32 \mathrm{~W}$ & $28.8 \mathrm{~W}$ & $-10 \%$ \\
\hline
\end{tabular}

Figure 9 depicts the inductance curves of the optimized nonlinear (saturable) inductor at $25^{\circ} \mathrm{C}$ and $100^{\circ} \mathrm{C}$. Both curves meet the specification and are very close to the lower inductance limit-particularly at the temperature in steady state of the application $\left(100^{\circ} \mathrm{C}\right)$. Now, the related construction can be compared to a (conventional) linear ferrite inductor. In Table 1 the basic parameters are listed. It is found that the size of the component (without housing and lead-outs) can be reduced by $32 \%$. As a direct consequence of the lower number of turns $(N=116$ instead of $N=144)$, the amount of copper and thus the copper losses can be reduced by $19 \%$. Of course, the core losses of Sendust $(\operatorname{CoolM} \mu)$ metal powder are higher in comparison to ferrite, but a $10 \%$ reduction of total power loss can finally be achieved. 


\section{Conclusions}

A practical method is presented: how to adjust the inductance curve of a nonlinear (saturable) inductor with respect to a desired shape. A 2D FEM approach is used for simulation and verified by experimental data. Using the described method, the specified input inductor of a practical PV inverter can be realized

(i) with $32 \%$ smaller size,

(ii) $19 \%$ less amount of copper,

(iii) $10 \%$ lower total power loss,

in comparison to a (conventional) linear ferrite inductor. As a direct consequence of the distributed air gap, minimum eddy current losses are achieved. The modular construction is scalable and causes much lower external stray fields (better EMC) than comparable inductors based on metal powder cores without any concentrated air gap(s).

\section{Conflict of Interests}

The validity of this research is not influenced by secondary interests, such as financial gains. Brand names are only given for the exemplification of technical aspects.

\section{References}

[1] W. H. Wölfle and W. G. Hurley, "Quasi-active power factor correction with a variable inductive filter: theory, design and practice," IEEE Transactions on Power Electronics, vol. 18, no. 1, pp. 248-255, 2003.

[2] C. Wilhelm, D. Kranzer, and B. Burger, "Development of a highly compact and efficient solar inverter with Silicon Carbide transistors," in Proceedings of the 6th International Conference on Integrated Power Electronics Systems (CIPS '10), March 2010.

[3] IEC 60404 6, "Magnetic Materials-part 6: methods of measurement of the magnetic properties of magnetically soft metallic and powder materials at frequencies in the range $20 \mathrm{~Hz}$ to $200 \mathrm{kHz}$ by the use of ring specimens, ed. 2.0," 2003.

[4] J. Rivas, J. M. Zamarro, E. Martin, and C. Pereira, "Simple approximation for magnetization curves and hysteresis loops," IEEE Transactions on Magnetics, vol. 17, no. 4, pp. 1498-1502, 1981.

[5] A. Iványi, Hysteresis Models in Electromagnetic Computation, Akadémiai Kiadó, Budapest, Hungary, 1997.

[6] A. Stadler, "A generalized model for rate-independent ferromagnetic hysteresis phenomena," Journal of Physics, vol. 268, no. 1, Article ID 012028, 2011.

[7] C. W. T. McLyman, Transformer and Inductor Design Handbook, Marcel Dekker, New York, NY, USA, 2nd edition, 1988.

[8] http://www.csc-mrc.com/. 

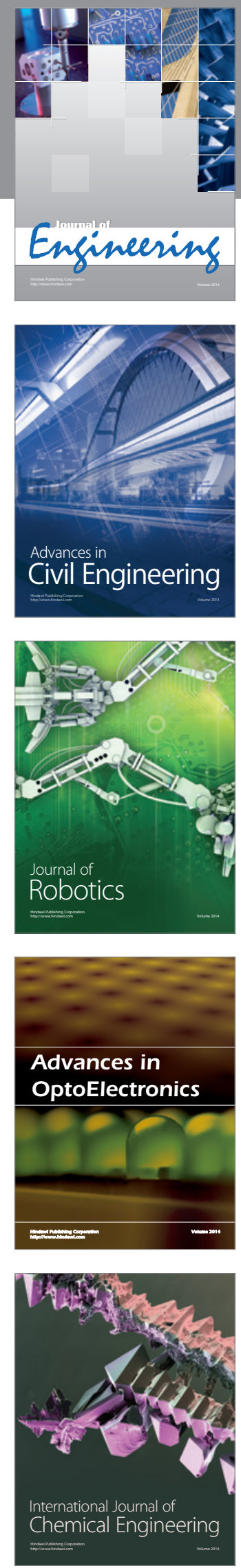

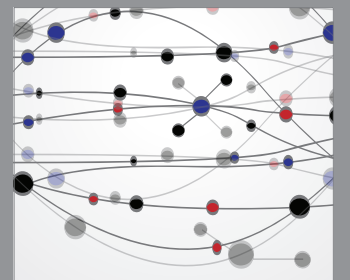

The Scientific World Journal
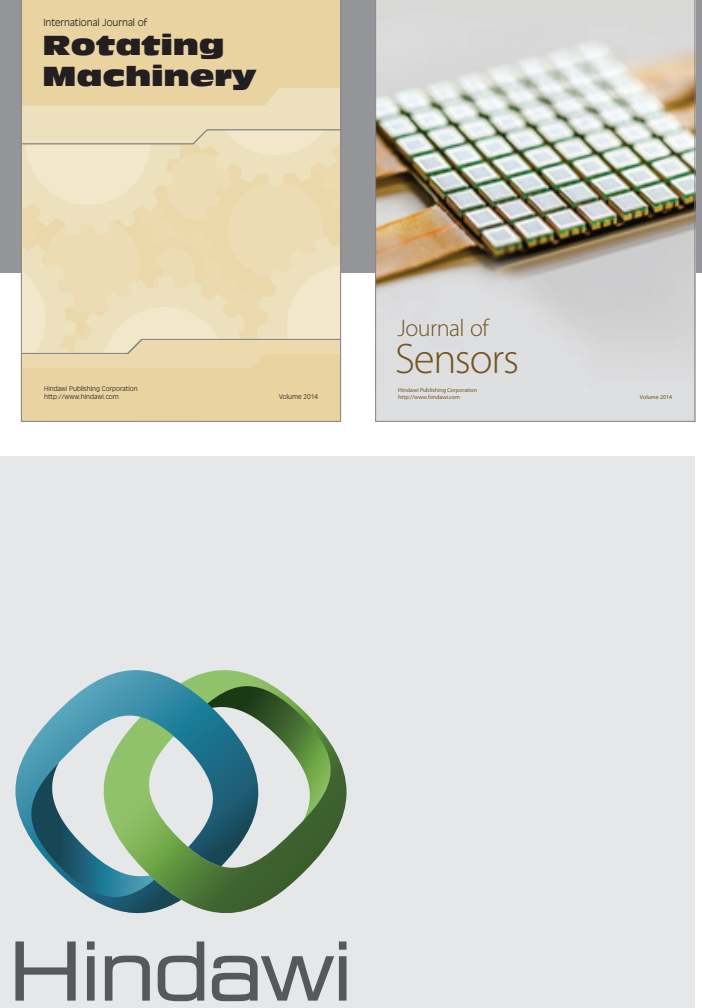

Submit your manuscripts at http://www.hindawi.com
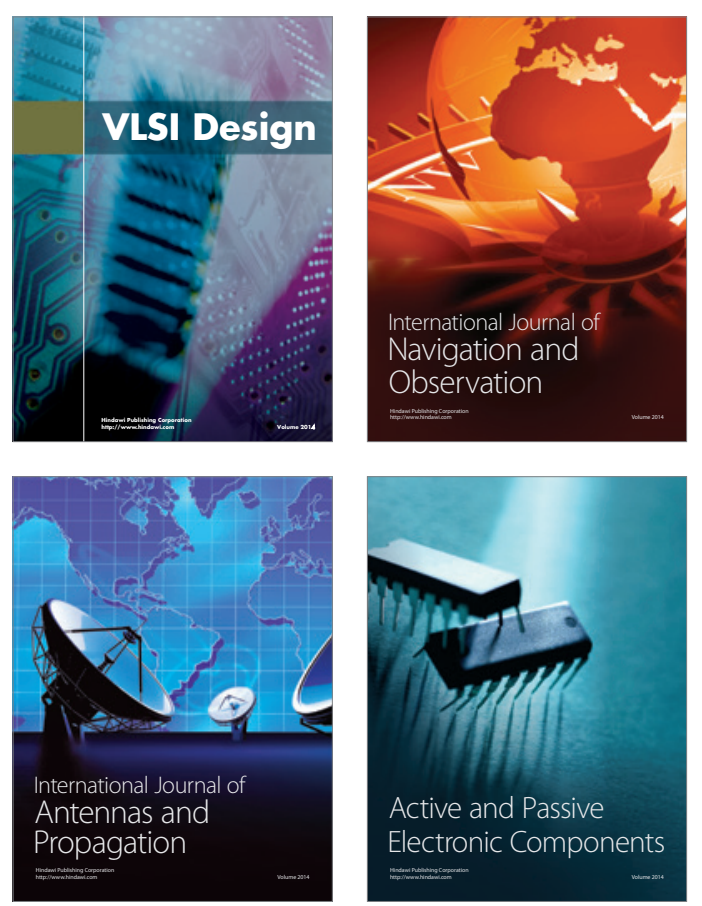
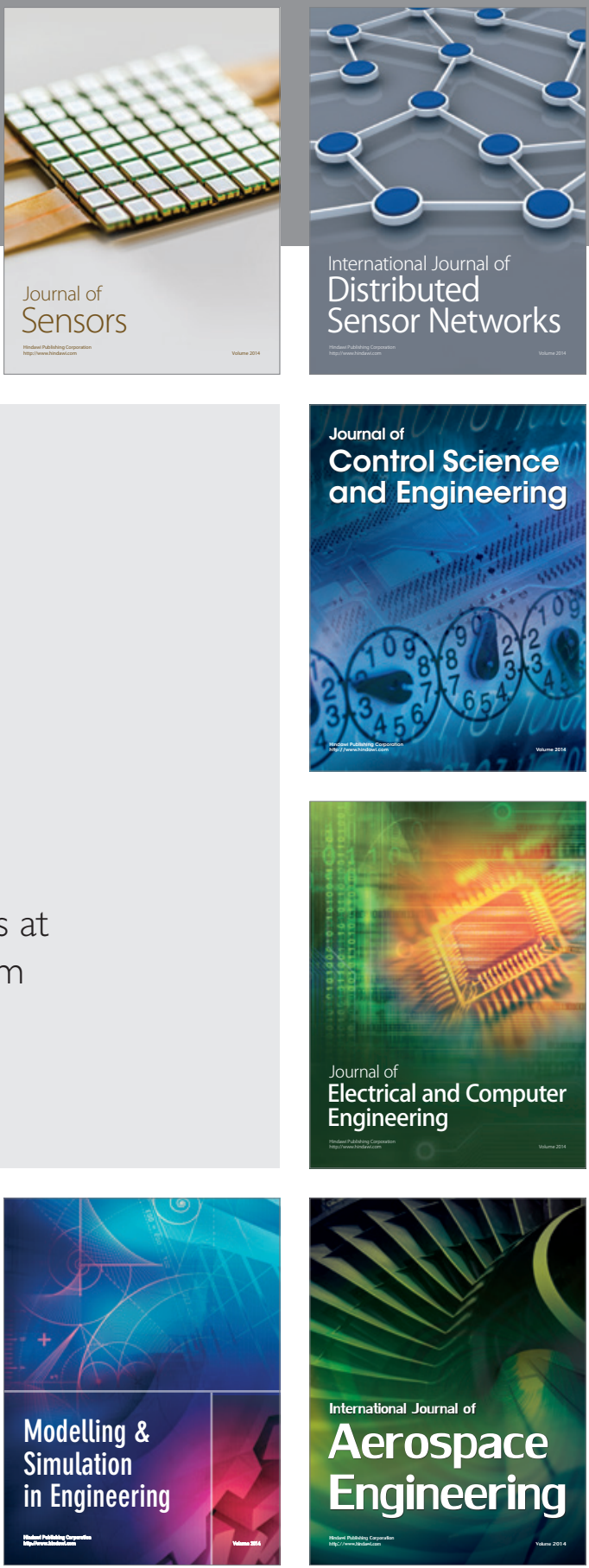

Journal of

Control Science

and Engineering
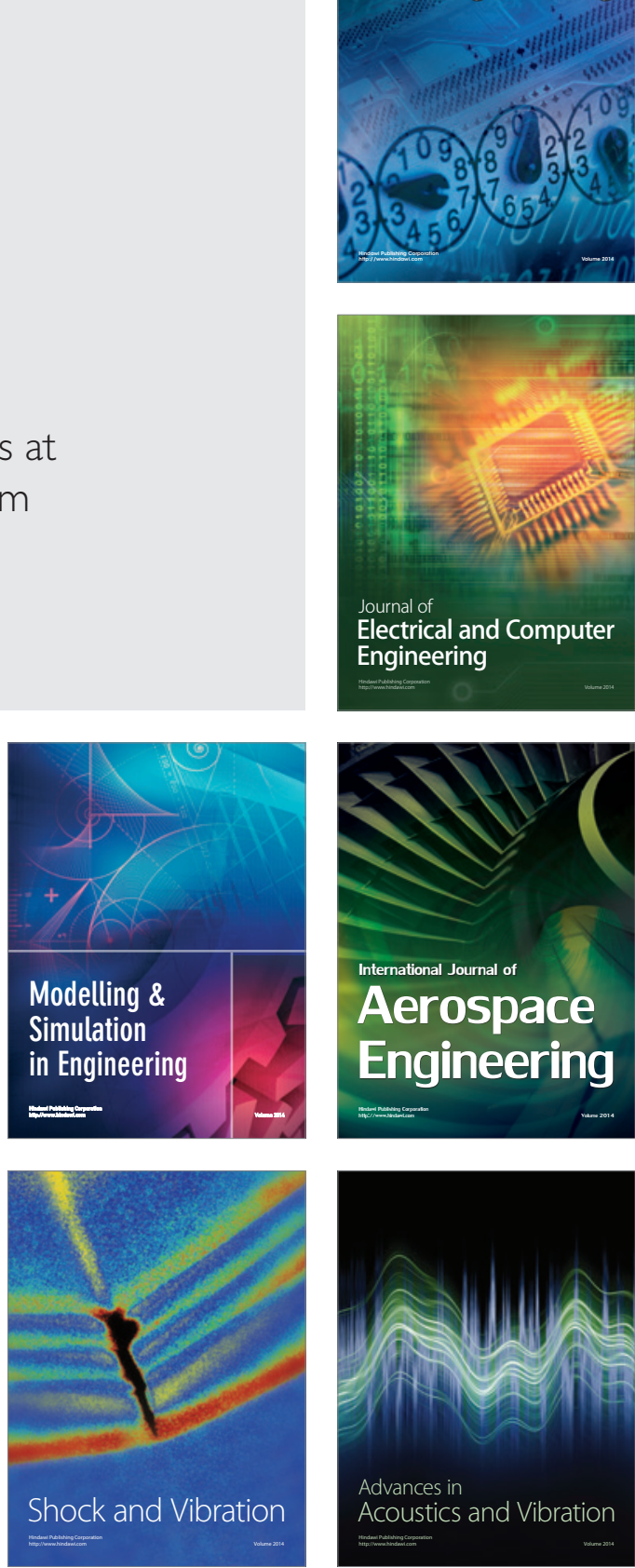